\title{
RUPTUR UTERI SEBAGAI KOMPLIKASI TOLAC PADA PASIEN DENGAN KETUBAN PECAH DINI
}

\author{
Rajudin $^{1}$, Kumalasari $^{2}$, Roziana ${ }^{1}$ \\ ${ }^{1}$ Staf Bagian Obstetri dan Ginekologi, Fakultas Kedokteran Universitas Syiah Kuala/Rumah Sakit Umum \\ dr. Zainoel Abidin Banda Aceh \\ ${ }^{2}$ Resident Bagian Obstetri dan Ginekologi, Fakultas Kedokteran Universitas Syiah Kuala/Rumah Sakit \\ Umum dr. Zainoel Abidin Banda Aceh \\ Corresponding author : rajud88@gmail.com
}

\begin{abstract}
Abstrak
Ruptur uteri inkomplit secara klinis signifikan terjadi setelah persalinan caesar sebelumnya dan merujuk pada gangguan lengkap dari semua lapisan uterus, kecuali serosa. Meskipun kejadiaanya sangat jarang, kurang dari $1 \%$ dari seluruh uji coba persalinan setelah kelahiran sesar (TOLAC). Komplikasi ini dapat memberikan outcome buruk termasuk komplikasi yang berhubungan dengan perdarahan berat, laserasi kandung kemih, histerektomi, dan morbiditas neonatal yang terkait dengan hipoksia intrauterin. Ruptur uteri inkomplit merupakan salah satu komplikasi TOLAC yang harus segera dikenali agar mendapatkan outcome maternal dan fetal yang lebih baik. Kami melaporkan satu kasus ruptur uteri inkomplit sebagai komplikasi TOLAC pada wanita multipara (G2P1A0) berusia 33 tahun hamil 39-40 minggu dengan ketuban pecah dini. Pasien menolak untuk terminasi kehamilan melalui tindakan seksio sesaria dan diputuskan untuk menjalani TOLAC dengan skor VBAC (Vaginal birth after cesarean delivery) adalah $2(60 \%)$ dan skor Weinstein $4(58 \%)$. Ketika observasi kemajuan persalinan pasien mengalami nyeri perut hebat, kontraksi hipertonik tanpa kelainan denyut jantung janin dan tanpa ring bundlesign. Pasien kemudian menjalani terminasi kehamilan perabdominal. Temuan intraoperatif menunjukkan suatu hematoma di bawah lapisan serosa sebagai akibat dari ruptur uterus inkomplit hingga ke lateral kiri. Setelah menjalani tindakan SC(Sectio Caesarea), ibu dan bayi dalam kondisi yang baik. Ruptur uteri inkomplit terjadi pada sekitar kurang dari $1 \%$ dari pasien yang menjalani TOLAC. Ketuban pecah dini yang terkait dengan abruptio plasenta dapat menjadi risiko terjadinya komplikasi ruptur uteri pada TOLAC. Namun, hal ini masih membutuhkan penelitian lanjutan. Sebagian besar ruptur uteri inkomplit asimptomatis atau menunjukkan gejala yang tidak khas. Pengenalan awal kondisi ini dapat menghasilkan outcome maternal dan fetal yang lebih baik.
\end{abstract}

Kata Kunci: ruptur uteri inkomplit, ketuban pecah dini, TOLAC 


\title{
Uterine Rupture as A Complication of TOLAC in Patients with Premature Rupture of Membranes (PROM)
}

\begin{abstract}
Clinically, partial uterine rupture is significant after previous cesarean delivery and refers to complete disruption of all uterine layers, except serosa. Although the incidence is very rare, less than $1 \%$ of all trials of labor after cesarean (TOLAC), these complication frequently results in poor maternal and fetal outcomes, including heavy bleeding, bladder lacerations, hysterectomy and neonatal morbidity associated with intrauterine hypoxia. Partial uterine rupture is one of the complications of TOLAC that must be immediately recognized in order to obtain better maternal and fetal outcomes. We reported a case of partial uterine rupture as a TOLAC complication in a 33-year-old multigravida (G2P1A0) with premature rupture of membrane (PROM). The patient refused to terminate the pregnancy through cesarean section, and thus TOLAC was performed, with a VBAC (Vaginal birth after cesarean delivery) score of $2(60 \%)$ and a Weinstein score of $4(58 \%)$. While observing the progress of labor, the patient experienced severe abdominal pain and hypertonic contractions without FHR abnormalities and Bandl's ring sign. Subsequently, the patient underwent a cesarean section. Intraoperative findings showed a hematoma below the serous layer as a result of partial uterine rupture to the left lateral. Both the patient and the baby were in good condition after the cesarean delivery. Partial uterine rupture occurs in approximately less than $1 \%$ of patients undergoing TOLAC. Premature rupture of membrane (PROM) associated with placental abruption can be a risk for uterine rupture in TOLAC patients. However, this still requires further researches. Most partial rupture are asymptomatic or show uncommon symptoms. Early recognition of these conditions can result in better maternal and fetal outcomes.
\end{abstract}

Keywords : partial uterine rupture, premature rupture of membrane, TOLAC 


\section{PENDAHULUAN}

Ruptur uteri secara klinis signifikan terjadi setelah persalinan caesar sebelumnya dan merujuk pada gangguan lengkap dari semua lapisan uterus, termasuk serosa, yang menyebabkan perubahan status ibu atau janin. ${ }^{1,2}$ Berdasarkan mekanisme nya ruptur uteri dapat dibedakan menjadi ruptur uteri komplit dan inkomplit. ${ }^{3}$ Kondisi ini merupakan komplikasi kehamilan yang mengancam jiwa baik bagi ibu dan janin. Outcome buruk lainnya termasuk komplikasi yang berhubungan dengan perdarahan berat, laserasi kandung kemih, histerektomi, dan morbiditas neonatal yang terkait dengan hipoksia intrauterin. ${ }^{4}$

Sebagian besar kasus ruptur uteri berhubungan dengan uji coba persalinan setelah kelahiran sesar (TOLAC). Berdasarkan tinjauan sistematis dari studi observasional TOLAC terkait dengan $0,62 \%$ tingkat ruptur uterus. ${ }^{5,6}$ Dimana lebih dari $90 \%$ kasus ruptur uteri terjadi pada wanita dengan riwayat sesar. ${ }^{7}$ Meskipun demikian, kemajuan persalinan pada ibu hamil yang mencoba TOLAC mirip dengan persalinan normal, dan tidak ada pola spesifik yang menyebabkan ruptur uteri. ${ }^{8,9}$

Sebagai komplikasi yang jarang terjadi, pengetahuan terkait dengan faktor risiko tidak terlalu akurat. Induksi persalinan sekuensial dengan prostaglandin dan oksitosin serta augmentasi persalinan dengan oksitosin merupakan faktor risiko penting untuk ruptur uteri pada uterus utuh atau uterus dengan bekas luka. ${ }^{10}$ Faktor risiko tersebut didukung dengan hasil penelitian tren 40 tahun ruptur uteri di Norwegia dimana faktor yang berkontribusi signifikan terhadap peningkatan kasus ruptur uteri adalah tingkat augmentasi yang lebih tinggi menggunakan oksitosin, bekas luka dari operasi sesar sebelumnya, dan induksi persalinan dengan prostaglandin atau prostaglandin yang dikombinasikan dengan oksitosin. ${ }^{11}$

Pada pasien dengan ruptur uteri, sebelum mengalami syok hipovolemik, gejala dan temuan pemeriksaan fisiknya mungkin tampak aneh. Hemoperitoneum dari uterus yang mengalami ruptur akan mengakibatkan iritasi diafragmatik dimana nyeri akan menjalar ke dada. ${ }^{12}$ Kami melaporkan kasus ruptur uteri inkomplit sebagai komplikasi TOLAC pada ibu multigravida dengan ketuban pecah dini. 


\section{LAPORAN KASUS}

Seorang wanita multipara (Gravida2 Para 1 Abortus 0) 33 tahun dengankeluhan keluar air-air 2 jam sebelum masuk rumah sakit, mules-mules dirasakan namun belum teratur, lendir darah tidak ada, gerak janin dirasakan aktif. Pasien mengaku hamil 9 bulan, hari pertama haid terakhir 19 Desember 2017, taksiran tanggal persalinan 26 September 2018 sesuai dengan usia kehamilan 39-40 minggu. Pasien ANC teratur di dokter spesialis obstetri dan ginekologi (Sp.OG) setiap bulan. Pemeriksaan ultrasonografi (USG) terakhir dikatakan janin dalam kondisi baik. Sejak awal hamil pasien sangat ingin untuk melahirkan normal, Sp.OG saat ANC menyarankan untuk melahirkan melalui operasi sesar (SC), mengingat TBJ saat itu sudah 3400 gr. Akhirnya Sp.OG tersebut mengirim pasien ke Sp.OG yang bertugas di RSUZA, mengingat RSUZA mampu melakukan SC dengan kurang dari 30 menit. Saat tiba di RSUZA pasien sangat ingin untuk mencoba lahir pervaginam dan bersedia dengan semua resiko nya. Pada persalinan sebelumnya, pasien hanya sampai pembukaan $5 \mathrm{~cm}$ namun karena tidak maju akhirnya di SC. Keputihan ada, gatal dan bau disangkal. Pada penilaian tanda vital stabil, kesadaran compos mentis dengan tekanan darah 110/70 mmHg, nadi $86 \mathrm{kali} / \mathrm{menit}$, suhu tubuh $36,6^{\circ} \mathrm{C}$ dan laju pernafasan $20 \mathrm{kali} / \mathrm{menit}$.

Pada pemeriksaan fisik umum tidak ditemukan kelainan. Hasil pemeriksaan status obstetrik dijumpai tinggi fundus uteri $34 \mathrm{~cm}$, punggung kiri, kepala 4/5, taksiran berat janin: 3410 gram, denyut jantung janin: $145 \mathrm{kali} /$ menit . Inspeksi vulva dan vagina tampak tenang serta tidak tampak perdarahan aktif. Dari pemeriksaan vaginal toucher, didapatkan portio posterior, lunak, belum ada pembukaan, kepala Hodge I-II. Tidak ditemukan fluksus, flour, valsava dan Nitrazin tes positif. Hasil pemantauan kardiotokografi diperlihatkan pada Gambar 1. Hasil pemeriksaan laboratorium awal dalam batas normal (Tabel 1). 


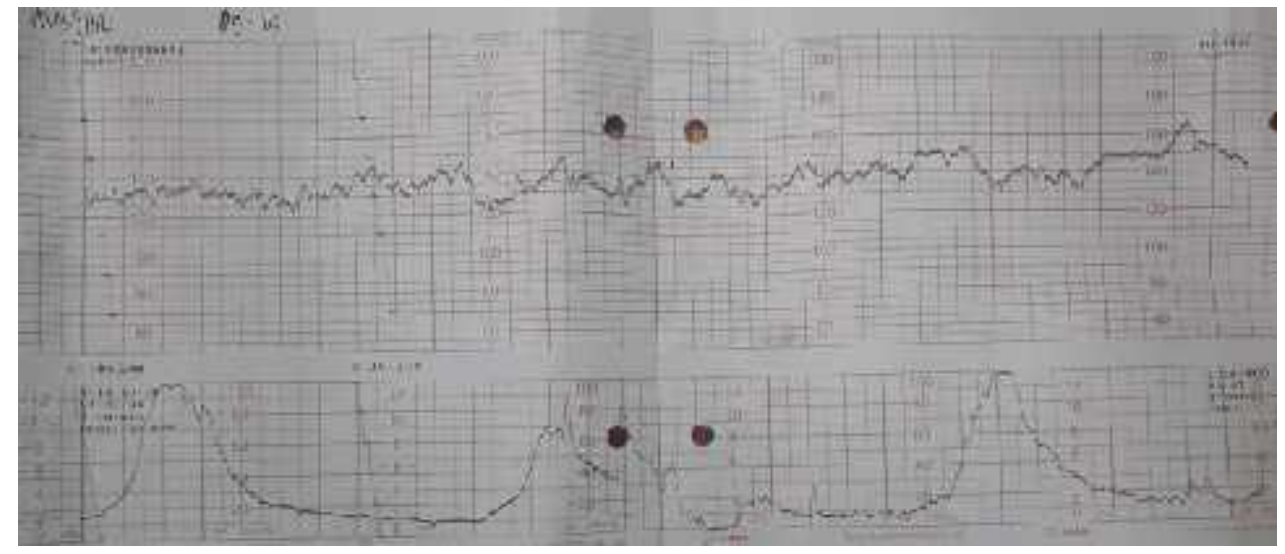

Gambar 1. CTG Kategori I [Baseline : 130 bpm; Variabilitas : 5-20 bpm; Akselerasi : $(+)>2 x / 10$ '; Deselerasi : (-); HIS : (+) 3 kali; Gerak janin : $(+)]$

Tabel 1. Hasil pemeriksaan laboratorium pasien

\begin{tabular}{ll}
\hline Jenis Pemeriksaan & Hasil Pemeriksaan \\
\hline Hemoglobin & $12,8 \mathrm{mg} / \mathrm{dl}$ \\
\hline Eritrosit & $4,7 \times 10^{6} \mathrm{sel} / \mu \mathrm{L}$ \\
\hline Trombosit & $427,3 \times 10^{3} \mathrm{sel} / \mu \mathrm{L}$ \\
\hline Hematokrit & $38 \%$ \\
\hline Leukosit & $15,4 \times 10^{3} \mathrm{sel} / \mu \mathrm{L}$ \\
\hline Gula darah sewaktu & $97 \mathrm{mg} / \mathrm{dL}$ \\
\hline HBsAg & $\mathrm{Negatif}$ \\
\hline Ureum & $17 \mathrm{mg} / \mathrm{dL}$ \\
\hline Kreatinin & $0,55 \mathrm{mg} / \mathrm{dL}$ \\
\hline
\end{tabular}

Pasien diagnosis dengan G2P1 hamil 39-40 minggu janin presentasi kepala tunggal hidup, bekas seksio sesarea 1 kali (IDT 6 tahun) dengan ketuban pecah dini belum inpartu. Pasien disarankan untuk menjalani tindakan SC mengingat skor VBAC rendah tapi menolak. Pasien kemudian diputuskan untuk menjalani TOLAC dengan skor VBAC $2(60 \%)$ dan skor Weinstein 4 (58\%) setelah sebelumnya mendapatkan antibiotik intravena. Dalam observasi kemajuan persalinan 2 jam kemudian didapatkan his 2 kali/10'/20". Observasi 4 jam, his 4 kali/10'/20”. Vaginal toucherportio kenyal, 
tebal $1 \mathrm{~cm}$, pembukaan $1 \mathrm{~cm}$, kepala Hodge II tapi pasien mengeluhkan nyeri perut hebat, ring bundle sign negatif, urine jernih. Selanjutnya ditemukan kontraksi hipertonik. Diputuskan untuk terminasi kehamilan perabdominal (SC).

Intra operatif, setelah peritoneum dibuka tampak uterus gravidus sesuai kehamilan aterm, tampak hematoma dibawah lapisan serosa (gambar 2), kesan rupturuteri inkomplit di bekas operasi lama. Diputuskan insisi $2 \mathrm{~cm}$ di atas segmen bawah rahim, ditembus dan dilebarkan tumpul. Air ketuban sedikit, dengan meluksir kepala, lahir bayi perempuan 3300 gr, $52 \mathrm{~cm}$, skor APGAR 8/9 dan skor Ballard 38- 40 minggu.

Implantasi plasenta dinilai, didapatkan plasenta berimplantasi di fundus, dengan tarikan ringan pada tali pusat, dilahirkan plasenta kesan lengkap. Pada eksplorasi tampak robekan segmen bawah rahim yang masih dilapisi lapisan serosa. Terjadi ruptur inkomplit hingga ke lateral kiri uterus, lapisan serosa robek saat meluksir bayi (Gambar

3A dan 3B).

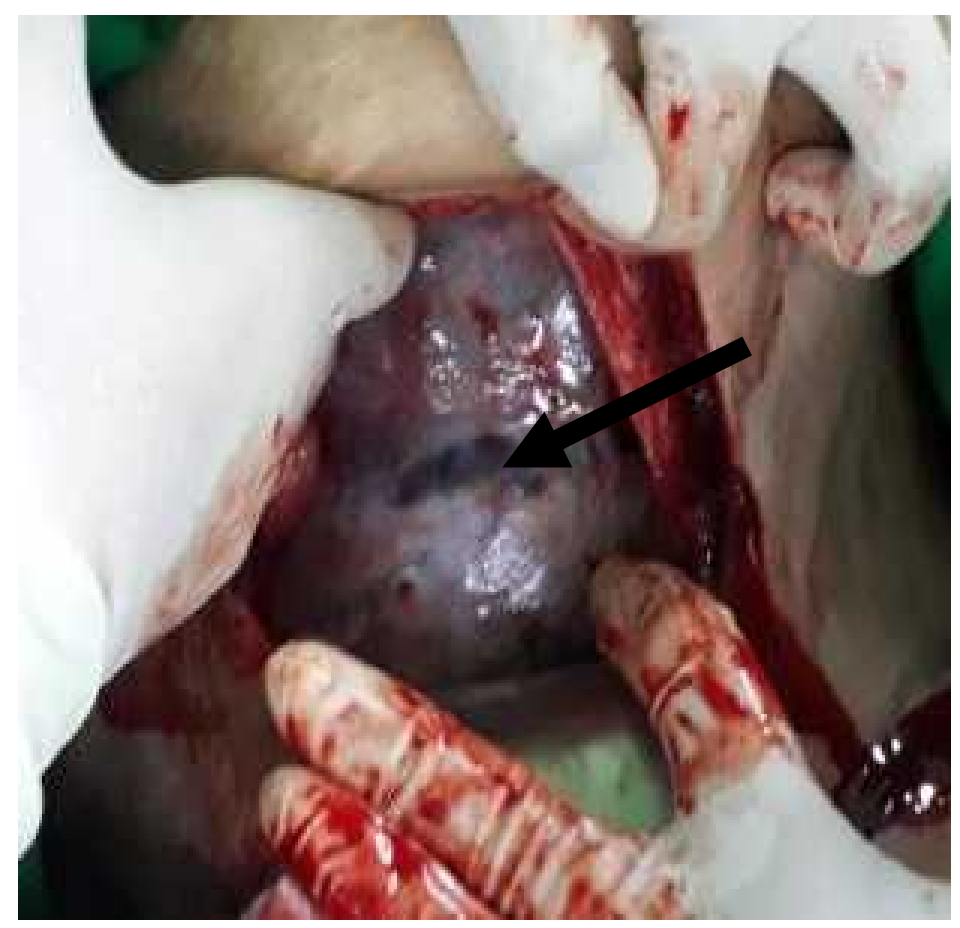

Gambar 2. Tampak uterus gravid dengan hematoma di bawah lapisan serosa (tanda panah). 

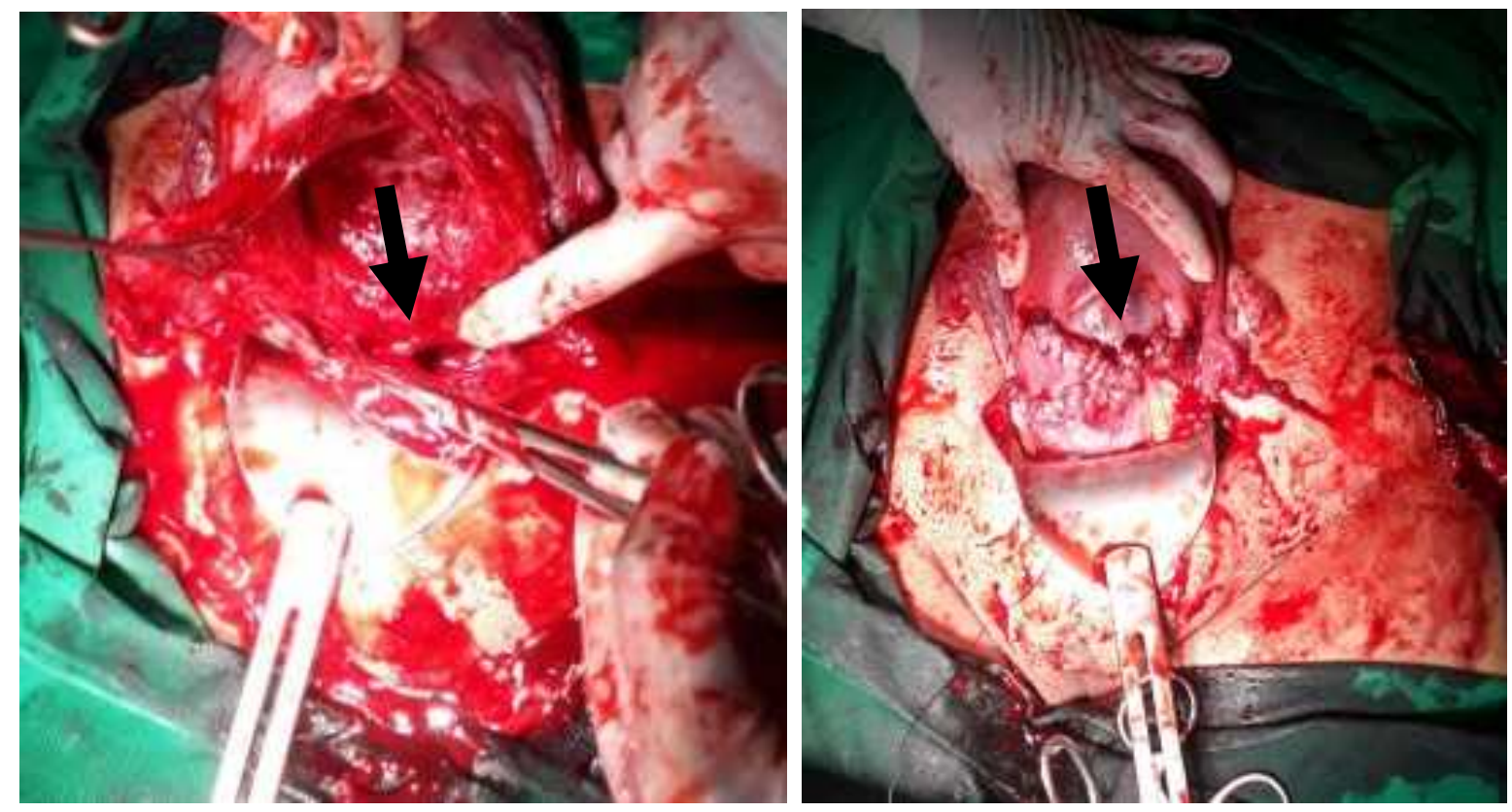

Gambar 3. A) tampak robekan segmen bawah rahim yang masih dilapisi lapisan serosa (tanda panah); B) rupturinkomplit hingga ke lateral kiri uterus, lapisan serosa robek saat meluksir bayi (tanda panah)

Bagian uterus yang robek dan juga insisi dijahit. Setelah diyakini tidak ada perdarahan, kontraksi rahim baik, sisi lateral kiri uterus hingga korpus posterior baik, tidak ada perdarahan. Pada eksplorasi kedua tuba dan ovarium dalam batas normal. Rongga abdomen dicuci dengan normal salin lalu kemudian ditutup lapis demi lapis. Estimasi perdarahan saat operasi $700 \mathrm{~mL}$. Kondisi ibu stabil pasca operasi.

\section{DISKUSI}

Kasus ini memaparkan setidaknya 2 masalah klinis. Pertama, ruptur uteri juga dapat terjadi sebagai komplikasi TOLAC pada pasien dengan pecah ketuban dini. Kedua, nyeri abdomen berat dengan kontraksi hipertonik tanpa tanda ruptur uteri klasik dan tanpa perubahan terhadap pemantauan kardiotokografi dapat dijadikan faktor dalam pengambilan keputusan yang cepat untuk kasus ruptur uteri inkomplit sebagai komplikasi TOLAC.

Ruptur uteri dibagi menjadi komplit dan inkomplit. Pada ruptur uteri komplit, serosa uterus bersama dengan lapisan otot uterus mengalami ruptur dan dengan 
demikian ketuban langsung berkomunikasi dengan rongga perut. Sedangkan pada ruptur uteri inkomplit, lapisan otot uterus mengalami robekan tetapi lapisan serosa uterus masih utuh. Ruptur uteri inkomplit disebut juga sebagai dehiscence uterus. ${ }^{3,11-13}$

Masalah klinis penting yang pertama adalah ruptur uteri inkomplit sebagai komplikasi TOLAC pada pasien dengan ketuban pecah dini (KPD). Ruptur uteri sangat jarang pada wanita yang menjalani TOLAC. Sebuah tinjauan sistematis menyimpulkan bahwa tingkat ruptur uterus simptomatik berkisar antara $0 \%$ hingga $0,78 \%$ pada ibu yang menjalani TOLAC dalam 10 penelitian observasional dengan tingkat gabungan 0,38\% (95\% CI 0,13\% -0,62\%). ${ }^{14}$ Dalam sebuah penelitian besar lainnya, tingkat ruptur uteri spontan pada pasien dengan bekas luka bedah caesar tunggal yang direncanakan menjalani tindakan SC elektif tanpa TOLAC adalah $0,16 \%{ }^{15}$

Meskipun demikian, tinjauan literatur tidak menunjukkan hubungan langsung patofisiologi antara KPD dengan kompromise miometrium yang menyebabkan ruptur uterus. Namun, KPD merupakan faktor predisposisi untuk abruptio plasenta, tapi tidak dapat ditentukan sebagai salah satu faktor penyebab ruptur uteri pada kasus kami. Penelitian berbasis populasi besar oleh Markhusetal pada tahun 2011 menunjukkan OR 2,6 untuk kejadian abruptio plasenta pada pasien dengan KPD dibandingkan populasi obstetrik umum. ${ }^{16}$ Penelitian kohort retrospektif besar yang dilakukan oleh Biosrameetal pada tahun 2014 menunjukkan OR 9,5 untuk KPD pada pasien dengan abruptio plasenta. Penelitian ini tentunya lebih memperkuat hubungan antara KPD dengan abruptio plasenta. ${ }^{17}$ Kehadiran rahim Couvelaire, yang sering dikaitkan dengan abruptio plasenta, serta bukti infark plasenta pada pemeriksaan histopatologi, secara efektif memutuskan kemungkinan abruptio plasenta. ${ }^{18,19}$

Meskipun tinjauan literatur tidak dapat mengidentifikasi hubungan kausatif antara abruptio plasenta dengan ruptur uteri terdapat beberapa bukti hubungan di antara kedua entitas ini. Analisis retrospektif 14 tahun terkait ruptur uteri oleh Turgutetal pada tahun 2013 menemukan bahwa abruptio plasenta merupakan patologi obstetri umum yang sering terjadi bersamaan dengan ruptur uterus, terjadi pada 1 dari 20 kasus. $^{20}$ Untuk alasan ini, penulis beranggapan bahwa dibandingkan ruptur spontan yang idopatik terjadi sebagai komplikasi TOLAC, salah satu kemungkinan penyebab ruptur 
uteri pada pasien kami adalah abruptio plasenta yang merupakan faktor predisposisi KPD.

Pada sebuah serial kasus Felmus set al melaporkan kasus dari seorang ibu hamil multipara pada jangka waktu tanpa faktor risiko yang diketahui yang datang dengan KPD dan kesejahteraan janin yang meyakinkan sebelum mengalami ruptur uteri. Dalam hal ini, evaluasi patologis uterus yang dikeluarkan oleh histerektomi sesar darurat menunjukkan infark miometrium yang luas dan nekrosis yang berdekatan dengan lokasi ruptur sekunder akibat trombosis arteri uterina. Felmusetal juga mengutip kasus-kasus ruptur uteri spontan lainnya yang berhubungan dengan infark miometrium dan trombosis arteri uterina. ${ }^{21}$ Apakah trombosis arteri uterus berkontribusi pada ruptur uteri dalam kasus kami akan tetapi tidak diketahui.

Masalah klinis yang kedua adalah gejala nyeri perut dengan kontraksi hipertonik tanpa tanda klasik ring bundle sebagai tanda dan gejala ruptur uteri inkomplit. Nyeri perut dan pola denyut jantung janin (FHR) yang non-reassuring, terutama bradikardia janin, telah dilaporkan sebagai tanda-tanda ruptur uterus yang akan segera terjadi atau dalam beberapa kasus. ${ }^{22,23}$ Laporan kasus kami menunjukkan adanya nyeri perut dan tanpa pola denyut jantung abnormal.

Penelitian yang dilakukan oleh Guilianoetal pada tahun 2014 dari total 97.028 kelahiran selama masa studi teridentifikasi 52 ruptur uteri $(0,05 \%) .27$ kasus merupakan ruptur uteri inkomplit. Sebagian besar (89\%) terjadi pada wanita dengan riwayat sesar sebelumnya. Pada ruptur yang lengkap, kelainan FHR adalah tanda yang paling sering (82\%), sedangkan trias rupturuteri komplit seperti kelainan FHR, perdarahan per vagina, dan nyeri hanya terjadi pada 9\%. Tanda dan gejala ruptur inkomplit sangat berbeda. Sebagian besar pasien asimtomatik (48\%). ${ }^{24}$ Tingkat kejadian ruptur uteri inkomplit dilaporkan antara 0,5 hingga 0,9\%. Meskipun insidennya lebih banyak dari pada ruptur komplit, frekuensi ruptur inkomplit asimtomatik mungkin telah diminimalkan oleh fakta bahwa separuh perempuan tidak menunjukkan gejala dan beberapa mungkin terlewatkan. ${ }^{25,26}$ 
Meskipun kasus ini jarang terjadi, klinis harus selalu waspada dan segera mengenali tanda-tanda terjadinya ruptur uteri terutama pada pasien TOLAC yang mengalami ketuban pecah dini.

\section{KESIMPULAN}

Ruptur uteri inkomplit terjadi pada sekitar kurang dari 1\% dari pasien yang menjalani TOLAC. Ruptur uterus adalah salah satu komplikasi TOLAC yang paling signifikan setelah bedah caesar sebelumnya. Mengidentifikasi mereka yang berisiko tinggi ruptur uterus sangat penting untuk keamanan TOLAC. Ketuban pecah dini yang terkait dengan abruptio plasenta dapat menjadi risiko terjadinya komplikasi ruptur uteri pada TOLAC. Namun, hal ini masih membutuhkan penelitian lanjutan. Sebagian besar ruptur uteri inkomplit asimptomatis atau menunjukkan gejala yang tidak khas. Pengenalan awal kondisi ini dapat menghasilkan outcome maternal dan fetal yang lebih baik. 


\section{REFERENSI}

1. Gupta J, Smith G, Chondankar R. Royal College of Obstetrician and Gynaecologists (RCOG) Green-top Guideline No. 45: Birth After Previous Caesarean Birth. $\mathrm{R}$ Coll Obstet Gynaecol Green-top Guidel [Internet]. 2015;45(45):31. Tersedia pada: https://www.rcog.org.uk/globalassets/documents/guidelines/gtg_45.pdf

2. Obstetricians AC of, Gynecologists. ACOG Practice bulletin no. 115: Vaginal birth after previous cesarean delivery. Obstet Gynecol. 2010;116(2 Pt 1):450.

3. Augustin G. Spontaneous Uterine Rupture. In: Acute Abdomen During Pregnancy [Internet]. Cham: Springer International Publishing; 2018. hal. 621-62. Tersedia pada: https://doi.org/10.1007/978-3-319-72995-4_16

4. Al-Zirqi I, Daltveit AK, Vangen S. Infant outcome after complete uterine rupture. Am J Obstet Gynecol. 2018;

5. Spong CY, Landon MB, Gilbert S, Rouse DJ, Leveno KJ, Varner MW, et al. Risk of uterine rupture and adverse perinatal outcome at term after cesarean delivery. Obstet Gynecol. 2007;110(4):801-7.

6. Chauhan SP, Martin JN, Henrichs CE, Morrison JC, Magann EF. Maternal and perinatal complications with uterine rupture in 142,075 patients who attempted vaginal birth after cesarean delivery: a review of the literature. Am J Obstet Gynecol. 2003;189(2):408-17.

7. Baskett TF, Kieser KE. A 10-year population-based study of uterine rupture. Obstet Gynecol. 2001;97(4):S69.

8. Harper LM, Cahill AG, Roehl KA, Odibo AO, Stamilio DM, Macones GA. The pattern of labor preceding uterine rupture. Am J Obstet Gynecol. 2012;207(3):210e1.

9. Sondgeroth KE, Stout MJ, Tuuli MG, Lopez JD, Macones GA, Cahill AG. 829: Does uterine resting tone have any clinical value in trial of labor after cesarean (TOLAC)? Am J Obstet Gynecol. 2017;216(1):S475.

10. Al-Zirqi I, Daltveit AK, Forsén L, Stray-Pedersen B, Vangen S. Risk factors for complete uterine rupture. Am J Obstet Gynecol. 2017;216(2):165-e1.

11. Al-Zirqi I, Stray-Pedersen B, Forsén L, Daltveit A, Vangen S. Uterine rupture: trends over 40 years. BJOG An Int J Obstet Gynaecol. 2016;123(5):780-7. 
12. Cunningham FG, Leveno KJ, Bloom SL, Dashe JS, Hoffman BL, Casey BM, et al. Prior Cesarean Delivery. In: Williams Obstetrics, 25e [Internet]. New York, NY: McGraw-Hill Education; 2018. Tersedia pada: http://accessmedicine.mhmedical.com/content.aspx?aid=1151908574

13. Singh A, Shrivastava C. Uterine Rupture: Still a Harsh Reality! J Obstet Gynecol India [Internet]. 2015;65(3):158-61. Tersedia pada: https://doi.org/10.1007/s13224014-0551-2

14. Guise J-M, McDonagh MS, Osterweil P, Nygren P, Chan BKS, Helfand M. Systematic review of the incidence and consequences of uterine rupture in women with previous caesarean section. Bmj. 2004;329(7456):19.

15. Lydon-Rochelle M, Holt VL, Easterling TR, Martin DP. Risk of uterine rupture during labor among women with a prior cesarean delivery. $\mathrm{N}$ Engl J Med. 2001;345(1):3-8.

16. MARKHUS VH, Rasmussen S, Lie SA, Irgens LM. Placental abruption and premature rupture of membranes. Acta Obstet Gynecol Scand. 2011;90(9):1024-9.

17. Boisramé T, Sananès N, Fritz G, Boudier E, Aissi G, Favre R, et al. Placental abruption: risk factors, management and maternal-fetal prognosis. Cohort study over 10 years. Eur J Obstet Gynecol Reprod Biol. 2014;179:100-4.

18. Elsasser DA, Ananth $\mathrm{C} \mathrm{V}$, Prasad V, Vintzileos AM, Investigators NJ-PAS. Diagnosis of placental abruption: relationship between clinical and histopathological findings. Eur J Obstet Gynecol Reprod Biol. 2010;148(2):125-30.

19. Francois KE, Foley MR. Antepartum and postpartum hemorrhage. Obstet Probl Pregnancies 5th ed Philadelphia, Pa Elsevier Churchill Livingstone. 2007;

20. Turgut A, Ozler A, Evsen MS, Soydinc HE, Goruk NY, Karacor T, et al. Uterine rupture revisited: Predisposing factors, clinical features, management and outcomes from a tertiary care center in Turkey. Pakistan J Med Sci. 2013;29(3):753.

21. Felmus LB, Pedowitz P, Nassberg S. Spontaneous rupture of the apparently normal uterus during pregnancy: a review. Obstet Gynecol Surv. 1953;8(2):155-72.

22. Walsh CA, Baxi L V. Rupture of the primigravid uterus: a review of the literature. Obstet Gynecol Surv. 2007;62(5):327-34.

23. Dow M, Wax JR, Pinette MG, Blackstone J, Cartin A. Third-trimester uterine rupture without previous cesarean: a case series and review of the literature. Am J Perinatol. 2009;26(10):739-44.

24. Guiliano M, Closset E, Therby D, LeGoueff F, Deruelle P, Subtil D. Signs, 
symptoms and complications of complete and partial uterine ruptures during pregnancy and delivery. Eur J Obstet Gynecol Reprod Biol. 2014;179:130-4.

25. Grossetti E, Vardon D, Creveuil C, Herlicoviez M, Dreyfus M. Rupture of the scarred uterus. Acta Obstet Gynecol Scand. 2007;86(5):572-8.

26. Guyot A, Carbonnel M, Frey C, Pharisien I, Uzan M, Carbillon L. Uterine rupture: risk factors, maternal and perinatal complications. J Gynecol Obstet Biol Reprod (Paris). 2010;39(3):238-45. 